\title{
Correspondence
}

\section{Protesting loudly about Prevent is popular but is it informed and sensible?}

BJPsych Bulletin has recently published several articles that were critical of the Prevent limb of the government's current counter-terrorism strategy, including a polemical article by Summerfield ${ }^{1}$ and a more thoughtful piece by Bhui. ${ }^{2}$ Criticisms of the strategy are not confined to the professions; the Home Affairs Select Committee enjoyed media attention recently by staging a similar critique, with a special session held in Bradford. ${ }^{3}$ However, objections to Prevent have included knee-jerk criticisms that have not stood up to closer scrutiny. When the BBC published an article suggesting that a child was referred for misspelling 'terraced' house, the Lancashire Constabulary's Police and Crime Commissioner, Clive Grunshaw, revealed that 'the police visit took place because of other worrying issues in the boy's school work, not just the "terrorist house" line'. 4 The Independent Terrorism Legislation Reviewer, David Anderson QC, has recommended that the strategy 'should be the subject of review by an independent panel', but he also advised that such a review should be open to the possibility 'that the problems have been exaggerated or misrepresented (as may have been the case in the "terrorist house" incident), either inadvertently or in pursuance of a political agenda'. ${ }^{5}$

Bhui and Summerfield ${ }^{1,2}$ made emotive suggestions that Prevent required mental health professionals to carry 'a high index of suspicion' of terrorism that some might interpret 'with zeal'. ${ }^{2}$ There was a call for 'doing away with policies without evidence', ${ }^{2}$ the most extreme suggestions being that the ideas underlying Prevent are 'of a piece with the era of McCarthyism in the USA of the 1950s' and that they are so harmful that attending Prevent training would be unethical. ${ }^{1} \mathrm{~A}$ more measured and balanced approach is needed.

The most substantive of these authors' ethical concerns relates to the contention that making disclosures to third parties (in this instance, Channel $^{6}$ ) would be to breach the confidentiality inherent in the fiduciary doctor-patient relationship. However, there is no absolute duty of medical confidentiality and there are already circumstances in which it can ethically be breached, including 'when a disclosure would be likely to assist in the prevention, detection or prosecution of serious crime'.7 The Prevent duty brings with it no legal change to our existing duties as doctors and it seems no different to the responsibility we might have in any other case where we believed a patient might be at risk of becoming involved in serious crime.

We, too, would object to a requirement that we monitor and report all unacceptable thoughts, but of course this is not what we are being asked to do. We are being asked to be more informed and better educated about a particular sort of criminal activity and to consider breaching confidentiality when appropriate, just as we would do in any other case where we believed this was necessary to prevent serious crime.

There is nothing within the Prevent strategy that would interfere with clinical judgement. Perhaps the greater risk is from those who boycott Prevent training and then find themselves making rash decisions, after failing to make use of opportunities to rehearse some of the dilemmas that this strategy could create. Indeed, we would suggest that such cases would be very similar to others where one becomes concerned about risks a patient may pose to others and which would normally be managed by thoughtful discussion within the clinical team and with one's peers, before one made a clinical decision that might include making a disclosure to a third party.

Running throughout the articles in the Bulletin were concerns that British Muslims risk alienation through the Prevent process and that psychiatrists are currently ill-equipped 'to separate beliefs that are benignly religious from those that include political motivations and incite violence, but are disguised through religious rhetoric'. ${ }^{2}$ There was also the erroneous contention that severe mental illness is of little importance overall in the area of terrorism. Islamophobic hate crime and misrepresentation of Muslims as terrorists deserve censure and, in some cases, criminal sanctions. But the problems in understanding what Prevent is about - evident here - may lie not with the Prevent strategy itself but the 'radicalisation' model. This is itself more hypothesis than empiricism and has been criticised within the literature on terrorism studies. ${ }^{8}$ Our reading of the literature is that such models are probably unhelpful in the psychiatric context and that a case-by-case analysis is preferable.

If a model is required, then a better one is that of grievance-fuelled targeted violence, a category that includes lone-actor terrorists, public figure assassins, school shooters and workplace attackers - groups which share important characteristics and risk factors. ${ }^{9-11}$ It is with such lone actors that psychiatrists are most likely to have contact, reflecting the evidence that here severe mental illness is of central importance. Other psychiatrists, in common with us, will have encountered cases where counter-terrorism police have been monitoring people whose 'radicalisation' proved to signal the onset of a psychotic illness, with delusional beliefs involving religiose and paranoid themes drawn - as is typical - from the surrounding cultural milieu.

Psychiatrists should be concerned with the well-being of people with mental illness, rather than the dictates of political correctness. Recent research has shown that $43 \%$ of so-called lone-actor terrorists have a history of mental illness - no doubt an underestimate given the limited access that the researchers had to any form of medical record. ${ }^{12}$ Psychiatrists deal with the mentally ill; they do not concern themselves with the mentally well. Cases where vulnerable patients are drawn towards violence or cloak their paranoid and delusional grievances in the flag of a terrorist cause are ones where multiagency working, including through the Prevent strategy, is to the benefit of all.

Whether we like it or not, the role of the psychiatrist involves the protection of society from violence resulting from mental illness, as well as preventing individuals with mental illness from ruining their lives by becoming involved in serious criminal acts. A reticence to do so where Islam is concerned is illogical and indefensible. It also seems to betray an ignorance 
of the fact that studies of terrorism have consistently found that a greater number of lone-actor incidents in Europe and the USA are perpetrated by right-wing extremists or white supremacists ${ }^{13,14}$ and that it is lone actors embracing far-right ideologies that pose a greater threat in Europe than Islamist ones, causing $48 \%$ of terrorism-related fatalities. ${ }^{15}$ It is unclear to us whether opponents of the Prevent strategy in healthcare would have similar qualms about using Prevent mechanisms with, for instance, a future potential Breivik. We can all deplore, with Summerfield, ${ }^{1}$ the way that poor - and possibly illegal British and US foreign policy decisions in Afghanistan and Iraq have had unintended consequences; but we cannot put the clock back. We may not like the way societal changes impinge on our professional duties, but this does not mean we are entitled to turn our back on them.

Jonathan Hurlow, consultant forensic psychiatrist, Birmingham and Solihull Mental Health NHS Foundation Trust, Birmingham, UK, email: jonathon.hurlow@nhs.net, Simon Wilson, consultant and honorary senior lecturer in forensic psychiatry, Barnet, Enfield and Haringey Mental Health NHS Trust and UCL Department of Security and Crime Science, London, UK and David V. James MA, MBBS, FRCPsych, consultant forensic psychiatrist, Theseus LLP, London, UK.

1 Summerfield D. Mandating doctors to attend counter-terrorism workshops is medically unethical. BJPsych Bull 2016; 40: 87-88.

2 Bhui K. Flash, the emperor and policies without evidence: counterterrorism measures destined for failure and societally divisive. BJPsych Bull 2016; 40: 82-84.

$3 \mathrm{BBC}$ News UK. Extremism discussion event held in Bradford by committee. 2016; 28 Jan (http://www.bbc.co.uk/news/uk-england-leeds35430645) (accessed 8 March 2016).

4 Gani A, Slawson N. Lancashire police criticise BBC over 'terrorist house' story. Guardian 2016; 21 Jan (http://gu.com/p/4g2ag/sbl) (accessed 8 March 2016).

5 Anderson D. Supplementary written evidence submitted by David Anderson Q.C. (Independent Reviewer of Terrorism Legislation) to Home Affairs Committee Countering Extremism Inquiry. 2016; 29 Jan (http://data.parliament.uk/writtenevidence/committeeevidence.svc/ evidencedocument/home-affairs-committee/countering-extremism/ written/27920.pdf) (accessed 8 March 2016).

6 HM Government. Revised Prevent Duty Guidance for England and Wales. HM Government, 2016 (https://www.gov.uk/government/ uploads/system/uploads/attachment_data/file/445977/ 3799 Revised Prevent_Duty Guidance_England_Wales_V2Interactive.pdf) (accessed 8 March 2016).

7 General Medical Council. Confidentiality. GMC, 2009 (http://www. gmc-uk.org/guidance/ethical_guidance/confidentiality.asp).

8 Borum R. Informing lone-offender investigations. Criminol Public Policy 2013; 12: 103-112.

9 Capellan JA. Lone Wolf Terrorist or Deranged Shooter? A Study of Ideological Active Shooter Events in the United States, 1970-2014. Stud Conflict Terrorism 2015; 38: 395-413.

10 Gruenewald J, Chermak S, Freilich JD. Distinguishing "Loner" Attacks from Other Domestic Extremist Violence: A Comparison of Far-Right Homicide Incident and Offender Characteristics. Criminol Public Policy 2013; 12: 65-91.

11 McCauley C, Moskalenko S, Van Son B. Characteristics of Lone-Wol Violent Offenders: a Comparison of Assassins and School Attackers. Perspectives on Terrorism 2013; 7: 4-24.

12 Corner E, Gill P. A False Dichotomy? Mental Illness and Lone-Actor Terrorism. Law Hum Behav 2015. 39: 23-34.

13 Spaaij R. Understanding Lone Wolf Terrorism: Global Patterns, Motivations and Prevention. Springer, 2012.

14 Gill P. Lone-Actor Terrorists: A Behavioural Analysis. Routledge, 2015
15 Ellis C, Pantucci R, van Zuijdewijn J, Bakker E, Gomis B, Palombi S, et al. Lone Actor Terrorism: Analysis Paper. Countering Lone-Actor Terrorism Series No. 4. Royal United Services Institute, 2016.

doi: 10.1192/pb.40.3.162

Author's reply: I cannot accept that the Prevent programme is of a piece with everyday psychiatric practice concerning safeguarding and confidentiality. Prevent is about spying and intelligence-gathering and this cannot be ducked.

Hurlow et al are wrong: historically there has been very little relationship between diagnosable mental illness and terroristic acts, which are almost always committed on political grounds. Indeed, most of the terroristic violence in the world is committed by states, not by private individuals. And although it is true that violent radicalised individuals may be from, say, the neo-Nazi right, no one imagines that Prevent was intended to capture anyone other than Muslims. Prevent is part of a wider effort, deeply self-serving, to objectify Muslim culture and religion as carrying explanations for terrorism, so obscuring what damage Western powers have wrought in the Middle East. ${ }^{1}$

1 Kundnani A. The Muslims are Coming!: Islamophobia, Extremism, and the Domestic War on Terror. Verso, 2014.

Derek Summerfield consultant psychiatrist, South London and Maudsley NHS Foundation Trust, London, and honorary senior lecturer, Institute of Psychiatry, Psychology and Neuroscience, King's College London, UK, email: derek.summerfield@slam.nhs.uk

doi: $10.1192 / p b .40 .3 .163$

\section{Secure services for patients should be needs based and locally available}

Dye et al's ${ }^{1}$ timely editorial on 'locked rehabilitation' highlights the need for a closer working relationship between local and specialist commissioners in order to achieve appropriate, least-restrictive local care provision. It also raises the question whether the emergence of locked rehabilitation units is caused by a reduction in open hospital or community-based rehabilitation facilities, combined with a difficulty in accessing low secure units.

In our experience, the pathway into locked rehabilitation is usually via acute in-patient facilities where treatment focus is on stabilisation of mental state and early discharge. In the absence of appropriate open or community-based rehabilitation facilities available locally within the National Health Service (NHS), patients requiring longer periods of rehabilitation are referred for locked rehabilitation in the private sector, usually out of area. A significant minority of these patients have a history of violence, including serious physical assault and fire-setting, but have neither been charged nor convicted.

Regardless of current or future risks, 'gatekeeping assessment' to low secure care on behalf of NHS England relies on the non-clinical requirement that the person has either serious offence charges pending or has been convicted of an offence. This becomes a barrier to accessing appropriate local secure care because in some areas police are reluctant to charge patients with long-term psychotic problems, as it may be clear that eventually they will receive a psychiatric

\section{Bulletin}

